Article

\title{
Numerical Simulation on the Transient Temperature Field of Anode Rodding in Aluminium Reduction Cells
}

\author{
Tuofu Li ${ }^{1}$, Wenju Tao ${ }^{1, *}$, Zhaowen Wang ${ }^{1, *}$, Xiaozhen Liu ${ }^{1}$ and Jianfeng Hou ${ }^{2}$ \\ 1 School of Metallurgy, Northeastern University, Shenyang 110819, China; tuofuli@hotmail.com (T.L.); \\ liuxiaozhencfd@163.com (X.L.) \\ 2 Department of chemical, Lvliang University, Lvliang 033000, China; hxhgx@llhc.edu.cn \\ * Correspondence: taowj@smm.neu.edu.cn (W.T.); wangzw@smm.neu.edu.cn (Z.W.); \\ Tel.: +86-024-8368-2831 (W.T. \& Z.W.)
}

Received: 30 October 2018; Accepted: 30 November 2018; Published: 5 December 2018

check for updates

\begin{abstract}
The temperature field of the anode rodding process is the root of most of problems related to the anode. A 3D transient thermal finite element model was developed, based on ANSYS in this paper. The temperature field of the rodding process was investigated using this model. The results were presented and analyzed in detail, including the transient temperature fields of different components in the anode, the characteristics of the cast iron solidification, and the cooling rate distribution. The conclusions were as follows. When the stub hole was filled up at $10 \mathrm{~s}, 30 \%$ by volume of cast iron was below the liquidus temperature. At $70 \mathrm{~s}$, the cast iron solidified completely. The cast iron close to the stub solidified prior to that close to the carbon. The solidification mode was intermediate-freezing. The solidifying sequence was vertically from bottom to top, indicating that shrinkage cavities were less likely to occur. The temperature of the stub was higher than the carbon, and portion at high temperature was concentrated around the stub hole. The cooling rate during solidification was $4.3^{\circ} \mathrm{C} \mathrm{s}^{-1}$ to $43.7^{\circ} \mathrm{C} \mathrm{s}^{-1}$, and the gradient on the radial direction was relatively obvious.
\end{abstract}

Keywords: aluminium reduction cell; numerical simulation; anode rodding; transient thermal analysis; cast iron solidification

\section{Introduction}

Anode is an essential part in modern aluminium reduction cells. Currently, a typical pre-baked anode assembly consists of steel-made stubs and a carbon block with holes for the stubs, connected by cast iron thimbles. The technological process, which is the so-called anode rodding process, has been shown in Figure 1. The stubs are cleaned up and straightened if needed, and put into stub holes. Then, molten cast iron at about $1400-1500{ }^{\circ} \mathrm{C}$ is poured from anode casting ladles into the gap between the stub and stub hole at a specific position on the work platform. After 2-3 min cool-down, the as-rodded anodes are on their way to the next step. 


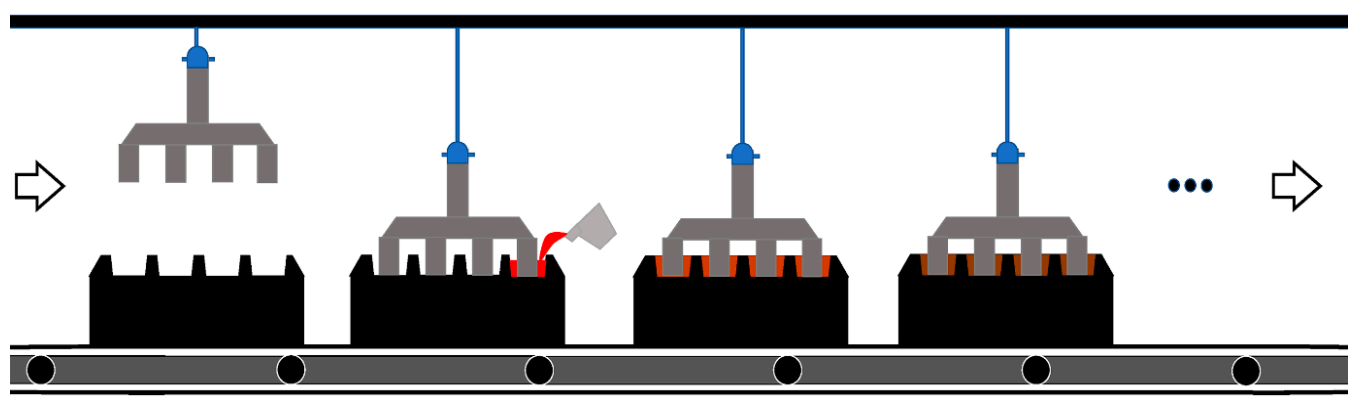

Figure 1. The schematic picture of rodding process in a smelter in China.

The temperature field during the rodding process has great influence on the subsequent anode performance under operation. Firstly, the temperature field directly affects the anode voltage drop. During cast iron solidification, the cast iron pulls away from the stub hole, forming a shrinkage gap that affects the contact voltage drop during cell operation, which is relative to temperature history during solidification. It was reported that poor casting process would result in an increase of the anode voltage drop of about $50 \mathrm{mV}$ [1]. Secondly, the cooling rate has great effects on the final phase and microstructure of the cast iron, affecting the performance of the cast iron, such as ultimate tensile strength (UTS), hardness, and elongation [2,3]. If the composition of the cast iron is fixed, the cooling rate at which cast iron passes through its liquidus temperature determines that the primary phase is austenite or graphite, and also its size and number [4], and the cooling rate can also determine whether the eutectic transformation is white or gray [5]. The cooling rate during solidification also has effects on the microstructure and phase distribution, such as dendrite arm space, secondary dendrite arm space [6], chill or reverse chill structure (cementite) [5], and segregation [7]. Besides, a bad rodding process would lead to defects. For instance, too low or too high a pouring temperature would bring about cold shut or hot tear $[4,8]$, which may increase the risk of carbon block falling. Through the cooling rate distribution and end-of-freeze isotherms, the shrinkage cavity or shrinkage porosity could be predicted [9]. Above all, the investigation on the distribution characteristics and laws of temperature, especially the period during cast iron solidification, is of great importance. It is the basis of the cast-to-carbon air gap, the cast iron microstructure, its physical properties, and so on.

Although Olivier et al. have succeeded in testing the temperature history of cast iron during the anode rodding process, it is difficult to implement such an experiment [10]. Firstly, as we know, the thickness of cast iron thimble is quite small compared to the dimension of stub and carbon, so that liquid cast iron cools down fast, which is very difficult to monitor. What is worse, the limited space and complex geometry cannot accommodate enough thermocouples to capture sufficient details in different positions. Secondly, it is better to use small size thermocouple and remove the sheath around the thermocouple in order to minimize the time delay in measurement [11]. However, the thermocouple is much more fragile, and it may be dissolved into or react with the molten cast iron, as the pouring temperature could be as high as $1400^{\circ} \mathrm{C}$. Lastly the maximum temperature of cast iron in stub hole is just around the maximum permitted temperature of the K-type thermocouple [12]. If an S-type thermocouple is adopted and the sheath has to be removed to minimize the time delay as mentioned above, the cost would be high, because the couples used in the molten cast iron without any protection can be used only once.

The investigation using a numerical simulation is a good way to study anode rodding. So far, there have been only a few reports about the numerical simulation of anode rodding. Gunasegaram et al. [2,13] have developed a transient thermo-mechanical finite element model, and the rodding process is numerically simulated using this model. However, they mostly concentrated on the phase distribution, mechanical properties, and crack tendency, with very little information about the temperature field. In addition, Urrutia et al. [3] have simulated the casting process, but this research focuses on the gray-to-white transformation during liquid cast iron solidification in anode rodding 
process, rather than the process itself. Above all, there has been no detailed or systematic thermal analysis on the anode rodding process.

Aiming at a detailed thermal analysis, in the present work, a transient thermal finite element model will be developed, based on which a numerical simulation of the rodding process will be conducted. In the simulation, the stub hole-filling process would be taken into account using the function "death and birth element", which could make the model more realistic. The results then obtained during the rodding process, especially for the period of the cast iron solidification, including temperature contour, solidification manner, cooling curves in some representative points, end-of-freeze plot, and cooling rate distributions, will be detailed and analyzed, so as to provide theoretical basis for the optimization of the rodding process, and further investigation.

\section{Model and Description}

\subsection{Geometry and Finite Element Model}

The geometry used in this paper refers to a 400-kA smelter in China. The anode design is based on four stubs, with six flutes for each stub hole. Due to the symmetry, only a half of the geometry is the computed domain so as to save computing time, as shown in Figure 2. The model is an assembly containing the carbon block, cast iron thimbles, steel stubs, aluminium rod, and the yoke.

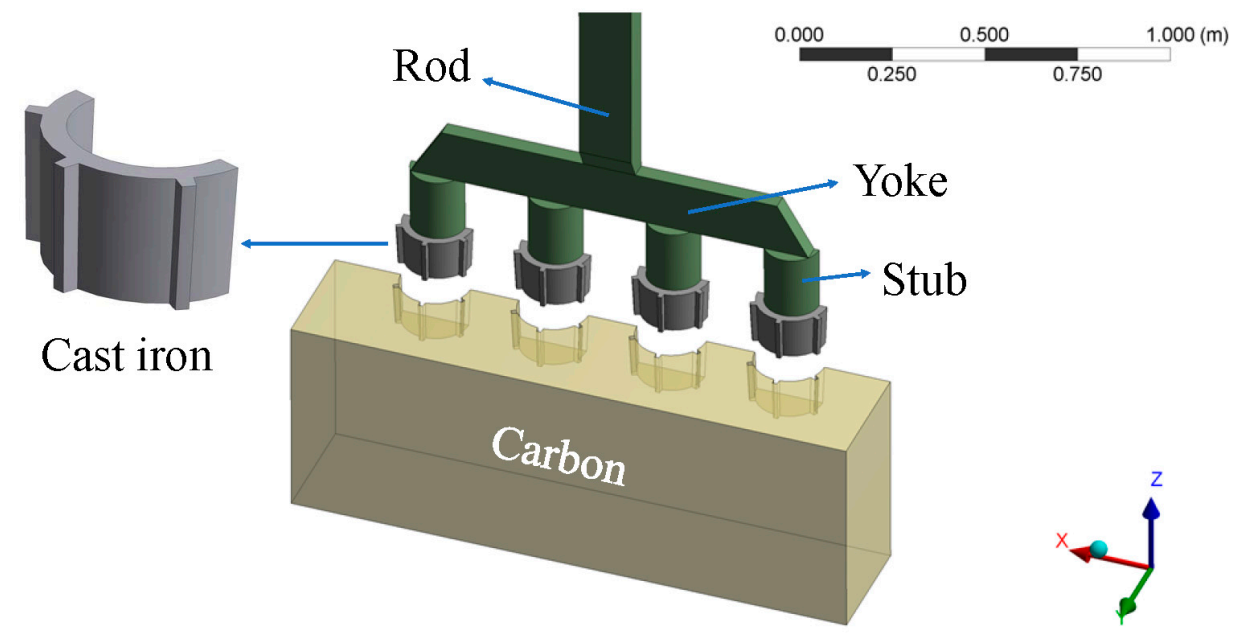

Figure 2. The geometry of the anode used in the present study.

The main dimensions of the model are listed in Table 1.

Table 1. Main dimensions of the model.

\begin{tabular}{cccc}
\hline Component & Dimension $(\mathbf{m m})$ & Component & Dimension $(\mathbf{m m})$ \\
\hline Carbon block & $1650 \times 680 \times 620$ & Anode rod length & 1500 \\
Stub diameter & 155 & Anode rod section & $150 \times 150$ \\
Stub hole depth & 120 & Stub hole diameter & $190-200$ \\
\hline
\end{tabular}

Since the mechanical behavior was not considered in the present study, the inclination of flutes was ignored. Figure 3 shows the dimensions of the stub hole. 

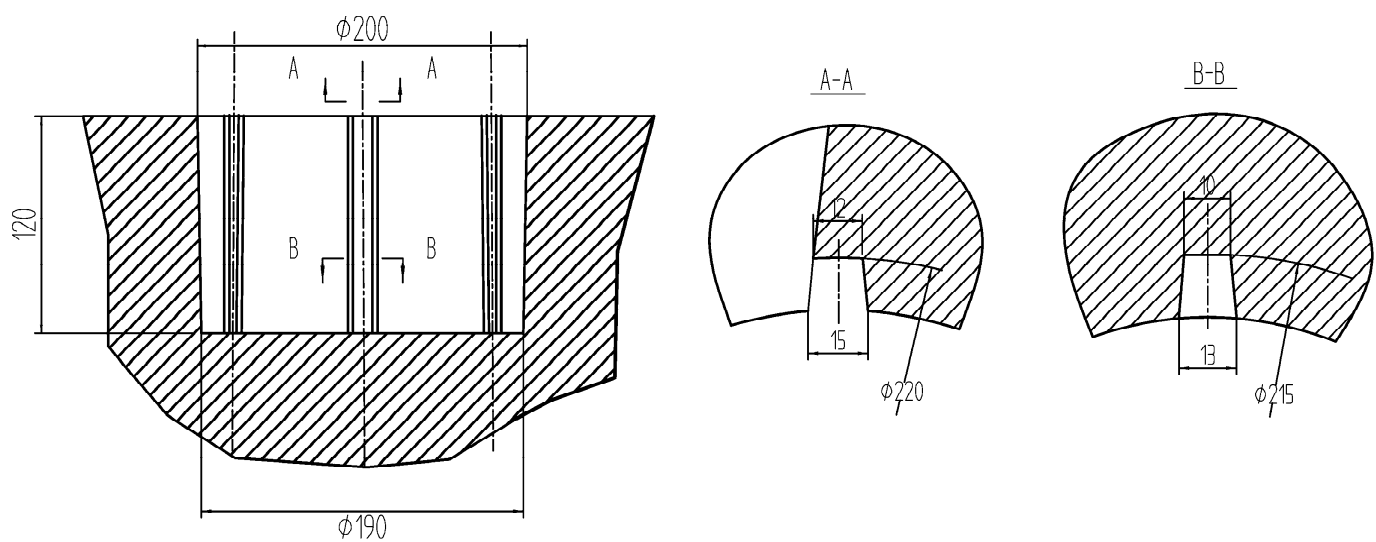

Figure 3. The internal structure and dimension of the stub hole (Unit: $\mathrm{mm}$ ).

Based on ANSYS Mechanical, Release 17.2 (ANSYS, Inc., Canonsburg, PA, USA), the solid model was meshed using 3D thermal element SOLID 70. The FE model is shown in Figure 4, and the mesh of the cast iron thimble and the part around was refined further. The elements CONTA 173 and TARGET 170 were used to handle the interfacial heat transfer issues between the cast iron thimble, the stub, and the stub hole. The development of the contact between cast iron and carbon is demonstrated, as shown in Figure 4. The geometrical interfaces between the cast iron and the carbon are located in the same position, but they are independent. The nodes on the two surfaces are also not linked, and the heat cannot transfer between the cast iron and the carbon. More importantly, there is interfacial thermal resistance between different materials. Thus, a relationship is needed between the nodes in different components. To address this, CONTA 173 was generated over the cast iron surface, and TARGET 170 was built to be attached to the surface of the carbon, constituting contact pairs. The pairs will act as a role of heat flow path with thermal resistance, which will be discussed in detail later.

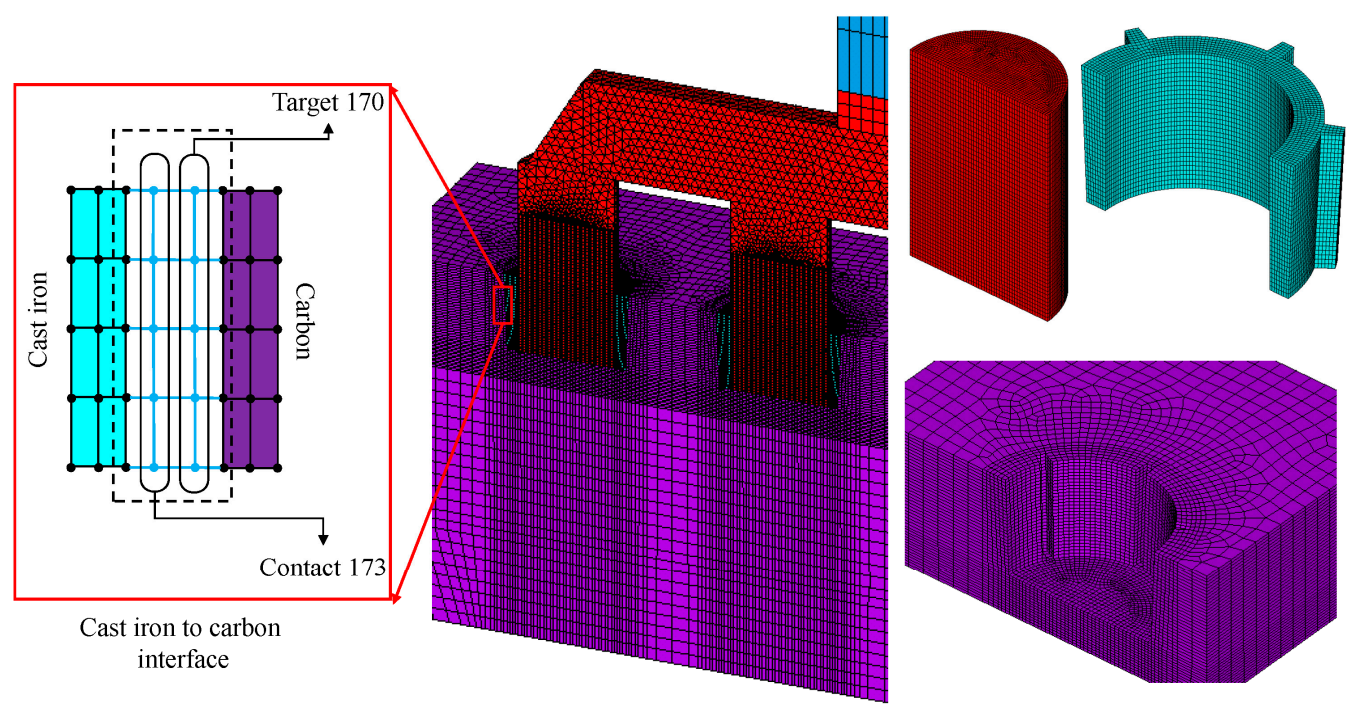

Figure 4. The finite element model with the schematic picture of contact pairs. 


\subsection{Governing Equation}

The finite element method was adopted due to its advantages in dealing with a complex geometry model. According to the heat transfer theory, the governing equation for three-dimensional heat-conductance is [14]:

$$
\frac{\partial}{\partial x}\left(\lambda_{x} \frac{\partial T}{\partial x}\right)+\frac{\partial}{\partial y}\left(\lambda_{y} \frac{\partial T}{\partial y}\right)+\frac{\partial}{\partial z}\left(\lambda_{z} \frac{\partial T}{\partial z}\right)+\dot{q}=\rho c_{p} \frac{\partial T}{\partial t}
$$

where, $\rho$ is the density, $\mathrm{kg} \cdot \mathrm{m}^{-3} ; c_{p}$ is the specific heat, $\mathrm{J} \cdot \mathrm{kg}^{-1} \cdot{ }^{\circ} \mathrm{C}^{-1} ; \mathrm{T}$ is the temperature, ${ }^{\circ} \mathrm{C}$; $t$ is the time, $\mathrm{s}$; $\dot{q}$ is the energy generated per unit volume, $\mathrm{W} \cdot \mathrm{m}^{-3} ; \lambda_{x}, \lambda_{y}, \lambda_{z}$, is the thermal conductivity, $\mathrm{W} \cdot \mathrm{m}^{-1} \cdot{ }^{\circ} \mathrm{C}{ }^{-1}$.

During the metal solidification process, the latent heat of phase change is an essential phenomenon that has significant effects on the temperature field. Usually, its thermal effect is treated as an inner heat source, as shown in Equation (2):

$$
\dot{q}=\rho L \frac{\partial f_{s}}{\partial t}=\rho L \frac{\partial f_{s}}{\partial T} \cdot \frac{\partial T}{\partial t}
$$

where, $f_{\mathrm{s}}$ is the solid phase percentage, a function of temperature during cast iron solidification; $L$ is the latent heat of phase change, $\mathrm{J} \cdot \mathrm{kg}^{-1}$;

Because $f_{s}$ is hard to get, the enthalpy is usually adopted instead. The enthalpy of cast iron at $T$ could be expressed as Equation (3):

$$
H=H_{0}+\int_{T_{0}}^{T} c_{p} d T+\left(1-f_{s}\right) L
$$

where, $H$ is the enthalpy at $T \cdot{ }^{\circ} \mathrm{C}, \mathrm{J} \cdot \mathrm{kg}^{-1} ; H_{0}$ is the enthalpy at standard temperature $\left(T_{0}\right), \mathrm{J} \cdot \mathrm{kg}^{-1}$.

Through transformation, the final governing equation, in which the latent heat of phase change is taken into account for cast iron, is as in Equation (4):

$$
\rho \frac{\partial H}{\partial \mathrm{t}}=\frac{\partial}{\partial x}\left(\lambda_{x} \frac{\partial T}{\partial x}\right)+\frac{\partial}{\partial y}\left(\lambda_{y} \frac{\partial T}{\partial y}\right)+\frac{\partial}{\partial z}\left(\lambda_{z} \frac{\partial T}{\partial z}\right)
$$

Above all, the precise material properties, appropriate boundary conditions, and initial conditions are required.

\subsection{Material Properties}

There were four materials involved in the model, including carbon, cast iron, steel, and aluminium. The physical properties of the carbon, steel, and aluminium, such as thermal conductivity, density, and specific heat, were taken from the literature [15]. The content of the elements of the cast iron are given in Table 2. The carbon equivalent (CE) was higher than $4.26 \%$, so that the cast iron could be classified into hypereutectic cast iron.

Table 2. The composition of the cast iron.

\begin{tabular}{cc}
\hline Element & Content/wt \% \\
\hline $\mathrm{Fe}$ & 92.11 \\
$\mathrm{C}$ & 2.94 \\
$\mathrm{Si}$ & 3.02 \\
$\mathrm{Mn}$ & 0.59 \\
$\mathrm{P}$ & 1.21 \\
$\mathrm{~S}$ & 0.13 \\
$\mathrm{CE}$ & 4.35 \\
\hline
\end{tabular}

* wt $\overline{(\mathrm{CE}) \%=\mathrm{wt}(\mathrm{C}) \%+(\mathrm{wt}(\mathrm{Si}) \%+\mathrm{wt}(\mathrm{P}) \%) / 3}[5]$. 
Usually, the cast iron greatly differs between recipes. Also, the composition from a same smelter could be different, due to different batches of raw materials. As a result, the properties are quite different. Since it is impractical to measure every recipe, a commonly applicable method was adopted in the present study. The curve of the material properties of the cast iron over time were calculated based on the elemental content and final phase composition using JMatPro version 7.0.0 (Sente Software Ltd, Guildford, UK), as shown in Figure 5. The calculation considered the effects of phase change on the properties. The dotted lines correspond to the liquidus temperature $\left(1172{ }^{\circ} \mathrm{C}\right)$ and solidus temperature $\left(980^{\circ} \mathrm{C}\right)$. The governing equation is based on thermal conductance law without the convective term, which should be taken into account when the cast iron is liquid. An artificial increase of the thermal conductivity is usually adopted [16]. As a result, in the curve of thermal conductivity, the value was specified as $100 \mathrm{~W} \cdot \mathrm{m}^{-1} \cdot{ }^{\circ} \mathrm{C}^{-1}$ after its temperature exceeded the liquidus temperature, while the convection in mushy zone were neglected [3].

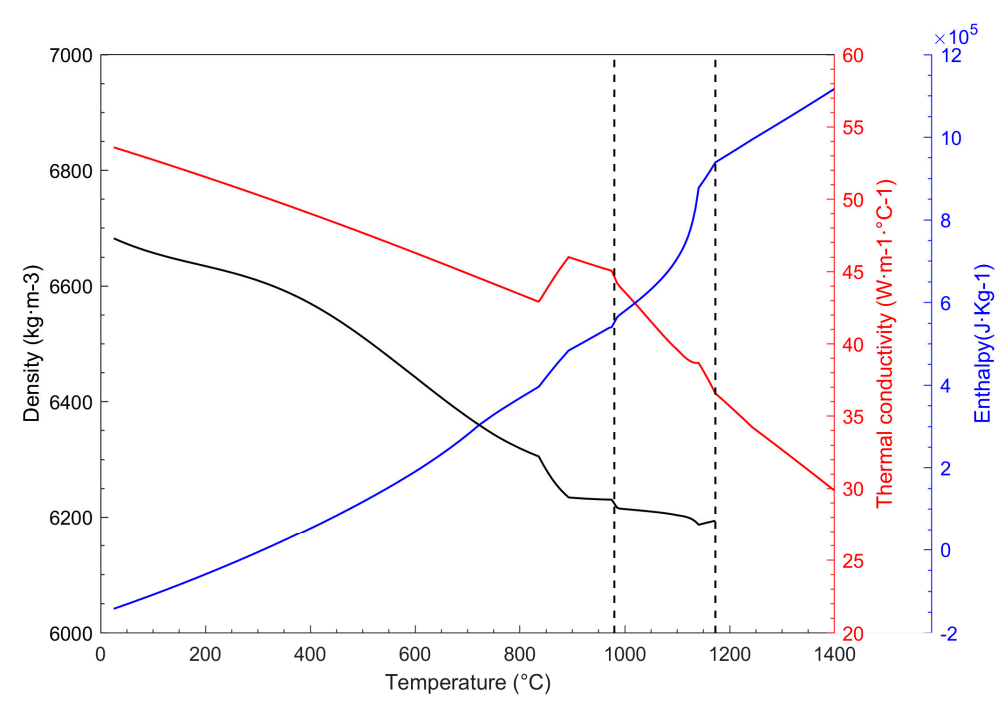

Figure 5. The curve of material properties over temperature.

\subsection{Initial Conditions and Boundary Conditions}

The rodding process could be considered as a casting process, in which cast iron is casting, while stub hole and stub are mold and chill, respectively.

The initial conditions were: 1 . All of the components were at room temperature, $20^{\circ} \mathrm{C}$, at $0 \mathrm{~s}$; 2. All the cast iron elements were deactivated and would be activated gradually with the stub hole-filling occurring, which was complimented by the "birth-death element" function.

Throughout rodding, the heat transfer at the interface between the cast iron and the carbon varied with different interfacial behaviors. Thus, the heat transfer between the cast iron and around was one of the key factors in the present study. Theoretically, there are four stages in heat transfer between casting and mold during the solidification process [17]: contact heat transfer, intermittent contact heat transfer, non-contact heat transfer affected by asperity, and non-contact heat transfer. Assuming that the metal and the mold are "perfect flat", the third stage and fourth stage are the same. Also, there is no process of intermittent contact, because the cast iron used in present study has a long freezing range. Besides, the contact quality was not taken into account. Hence, interfacial heat transfer during the rodding process was simplified to two stages, the contact stage and the air gap opening stage, respectively. In the first stage, the liquid cast iron contacted the carbon tightly under gravity force and static pressure. Then, once the temperature reached $980^{\circ} \mathrm{C}$, the cast iron thimble pulled away from the stub hole walls, due to the bad wettability between cast iron and carbon, as well as the shrinkage, and the heat transfer switched to the second stage, in which the heat transfer became worse. 
In contrast, cast iron could contact the stub tightly throughout the whole process, so that the heat transfer would be better. The schematic picture of the boundary conditions around the cast iron is shown in Figure 6.
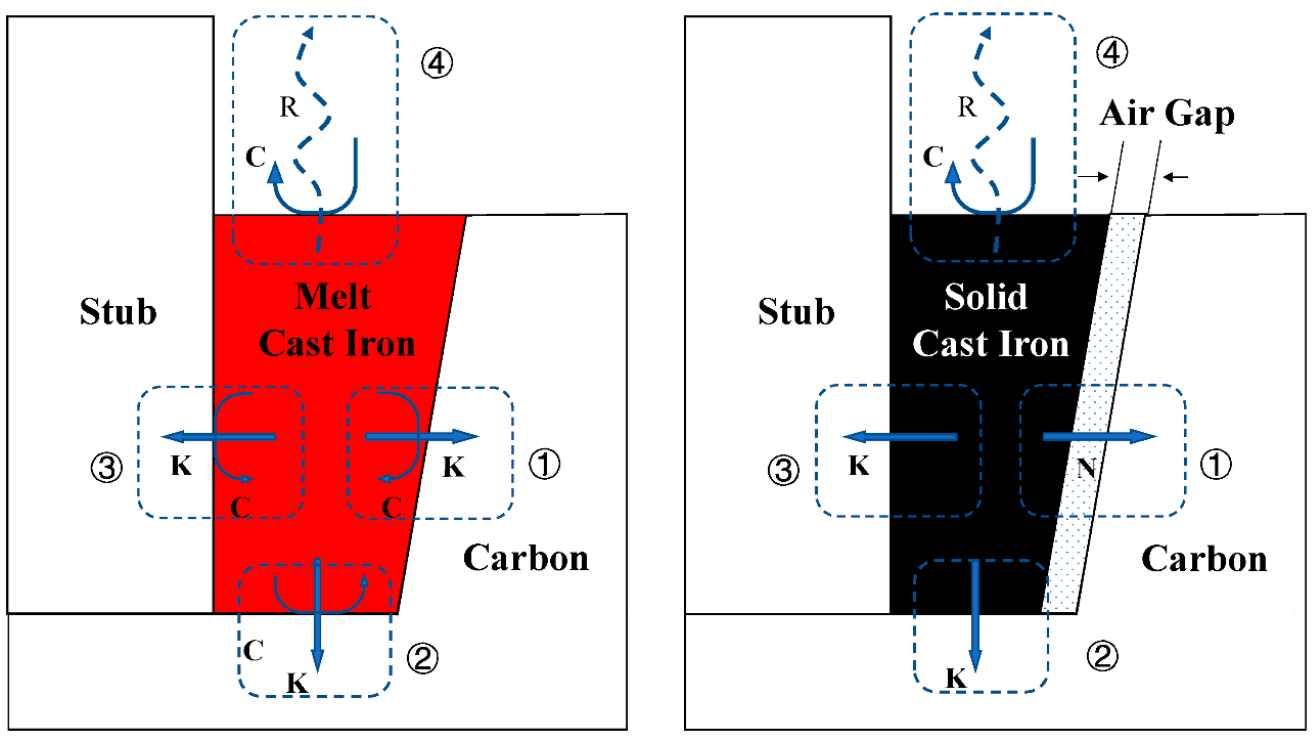

Figure 6. Boundary conditions around cast iron.

$\mathrm{C}, \mathrm{K}, \mathrm{R}$, and $\mathrm{N}$ represent heat convection, conductance, radiation, and interfacial heat transfer in the non-contact area, respectively.

Since the fluidity of the melt was not considered, the heat convection was equivalent to an increase of the thermal conductivity of the melt. The boundary conditions around the cast iron would be depicted as the order of the number marked in Figure 6 .

Boundary condition (1) is the heat transfer from the cast iron to the lateral wall of the stub hole, which is the most complicated, because of the variation with the contact state. Usually, there are three different strategies for the interfacial heat transfer coefficient between cast iron to carbon. In [2], the interfacial coefficient was presented as a function of a gap, ranging from $100 \mathrm{~W} \cdot \mathrm{m}^{-2} \cdot{ }^{\circ} \mathrm{C}^{-1}$ to $1000 \mathrm{~W} \cdot \mathrm{m}^{-2} \cdot{ }^{\circ} \mathrm{C}^{-1}$, while in [10], the coefficient was fitted as a function of time, decreasing from $800 \mathrm{~W} \cdot \mathrm{m}^{-2} \cdot{ }^{\circ} \mathrm{C}^{-1}$ to $400 \mathrm{~W} \cdot \mathrm{m}^{-2} \cdot{ }^{\circ} \mathrm{C}^{-1}$ with time. In [3], it was temperature-related. The coefficients below $1100{ }^{\circ} \mathrm{C}$ and above $1200{ }^{\circ} \mathrm{C}$ were constants, $500 \mathrm{~W} \cdot \mathrm{m}^{-2} \cdot{ }^{\circ} \mathrm{C}^{-1}$ and $1000 \mathrm{~W} \cdot \mathrm{m}^{-2} \cdot{ }^{\circ} \mathrm{C}^{-1}$ respectively, and the coefficients between the two temperatures were obtained through interpolation. Because the air gap was not considered in neither geometry nor finite element model, and parameters in the formula of the time-temperature curve are usually not constant in different cases, the temperature-related coefficient was adopted.

In this paper, different interfacial heat transfers scenarios between cast iron and carbon were equivalent to the variation of thermal contact conductivity, based upon Newton's law of cooling, as shown in Equation (5):

$$
q=T C C \times\left(T_{t}-T_{c}\right)
$$

where, $q$ is the heat transfer rate per area, $\mathrm{W} \cdot \mathrm{m}^{-2}$; TCC is short for thermal contact conductivity, $\mathrm{W} \cdot \mathrm{m}^{-2} \cdot{ }^{\circ} \mathrm{C}^{-1} ; T_{t}$ and $T_{c}$ represent the temperature at the target area and contact area respectively, ${ }^{\circ} \mathrm{C}$.

It is reasonable to adopt $1000 \mathrm{~W} \cdot \mathrm{m}^{-2} \cdot{ }^{\circ} \mathrm{C}^{-1}$ as TCC in the contact stage, while in the air gap opening stage, it switched to $500 \mathrm{~W} \cdot \mathrm{m}^{-2} \cdot{ }^{\circ} \mathrm{C}^{-1}$. The TCC in the air gap opening stage derived from the value when the air gap was $0.5 \mathrm{~mm}$ in [2], and it was overestimated because the air gap is usually wider than $0.5 \mathrm{~mm}$, according to the results in references $[2,10,18]$.

Boundary condition (2) is the heat transfer from the cast iron to the stub hole bottom. It was considered that the bottoms of the cast iron and the stub hole kept in touch under the gravity force. 
So, the TCC was specified as a constant with a value of $1000 \mathrm{~W} \cdot \mathrm{m}^{-2} \cdot{ }^{\circ} \mathrm{C}^{-1}$ which is equal to the value of cast iron-to-carbon TCC without air gap.

Boundary condition (3) is the heat transfer from the cast iron to the stub. Apart from (1), it is another key factor. In [3], the cast-to-stub TCC was completely the same as the TCC between the cast and carbon. Similarly, the fitted results in [10] decreased from about $950 \mathrm{~W} \cdot \mathrm{m}^{-2} \cdot{ }^{\circ} \mathrm{C}^{-1}$ to $720 \mathrm{~W} \cdot \mathrm{m}^{-2} \cdot{ }^{\circ} \mathrm{C}^{-1}$ with time. However, the cast-to-stub TCC should be much higher than that between the cast and the carbon, due to three reasons. Firstly, the wettability between the melt iron and the steel stub is much better than that between the cast and the carbon. Secondly, the solidified cast iron definitely contacts the stub tightly enough to bear the gravity of the anode assembly during cell operation. Lastly, the thermal conductivity of the steel is much higher than the carbon and the TCC is affected by the properties of the contacting materials. As a result, the TCC between the cast iron and stub was adopted as a constant, $2500 \mathrm{~W} \cdot \mathrm{m}^{-2} \cdot{ }^{\circ} \mathrm{C}^{-1}$, when the air gap equaled $0.0 \mathrm{~mm}$, according to reference [13].

Boundary condition (4) is the heat transfer between the cast iron top and the air via heat convection and radiation [14]. Generally, heat radiation could be equivalent to heat convection, resulting in heat transfer coefficient of radiation under the emissivity that was equal to 0.5 [19] in this case. Thus, the multimode heat transfer coefficient, which was adopted as the sum of coefficients of heat convection between the cast iron and the air and radiation, was a function of temperature, as shown in Figure 7.

According to [3], the TCC between the stub bottom and the carbon were the same as the cast iron-to-carbon TCC. However, in the present study, the stub was assumed to be tightly in contact with the stub hole bottom. Thus, it was specified as a constant $1000 \mathrm{~W} \cdot \mathrm{m}^{-2} \cdot{ }^{\circ} \mathrm{C}^{-1}$. Besides, the heat convection coefficient between all the surfaces (except the cast iron) and the ambient was $30 \mathrm{~W} \cdot \mathrm{m}^{-2} \cdot{ }^{\circ} \mathrm{C}^{-1}[13]$.

All the boundary conditions are summarized in Table 3.

Table 3. Boundary conditions summary.

\begin{tabular}{|c|c|c|}
\hline Heat transfer mode & Boundary conditions & Coefficient $\left(\mathrm{W} \cdot \mathrm{m}^{-2} \cdot{ }^{\circ} \mathrm{C}^{-1}\right)$ \\
\hline \multirow{3}{*}{ Thermal contact conductance } & Cast iron-Carbon & $\begin{array}{c}1000\left(T \geq 1172^{\circ} \mathrm{C}\right) \\
500\left(T<1172^{\circ} \mathrm{C}\right)\end{array}$ \\
\hline & Cast iron-Stub & 2500 \\
\hline & Stub-Carbon & 1000 \\
\hline Convection heat transfer & Stub, Yoke, Rod, Carbon-Air & 30 \\
\hline Multimode heat transfer & Cast iron-Air & Variable as in Figure 7 \\
\hline
\end{tabular}

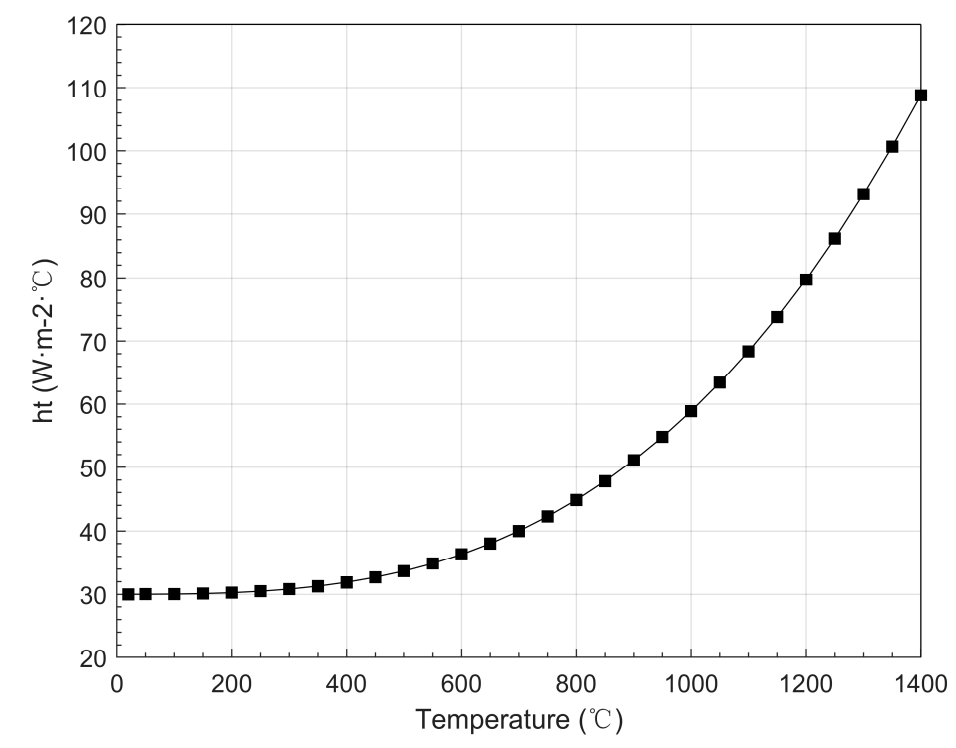

Figure 7. The multimode heat transfer coefficient over temperature. 


\subsection{Stub Hole-Filling Process}

According to the information from smelters in China, the pouring temperature of cast iron is usually between $1400-1500{ }^{\circ} \mathrm{C}$. Heat would dissipate into the air during pouring process, so that the temperature of the melt cast iron was set as $1350^{\circ} \mathrm{C}$. Assuming that liquid cast iron had constant filling speed and uniform composition, the $10 \mathrm{~s}$ filling process for each stub hole was equally divided into 10 steps, and for each step, the liquid cast iron increased by $1 / 10$ in height. The increment of cast iron would remain at $1350{ }^{\circ} \mathrm{C}$ in the current load step. As shown in Figure 8, the load switching between the adjacent steps is illustrated.

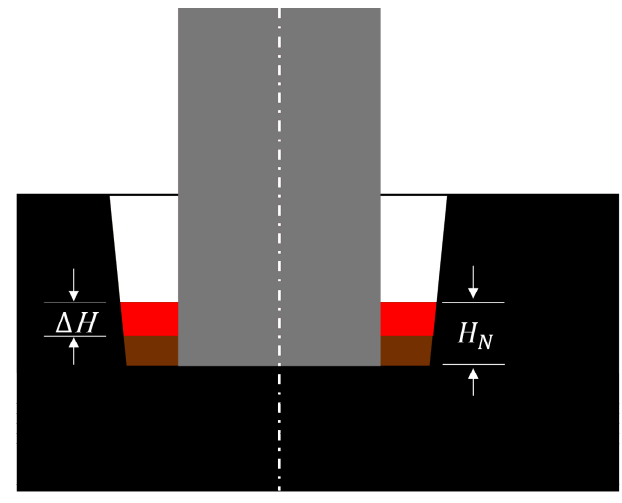

$t=N$ second

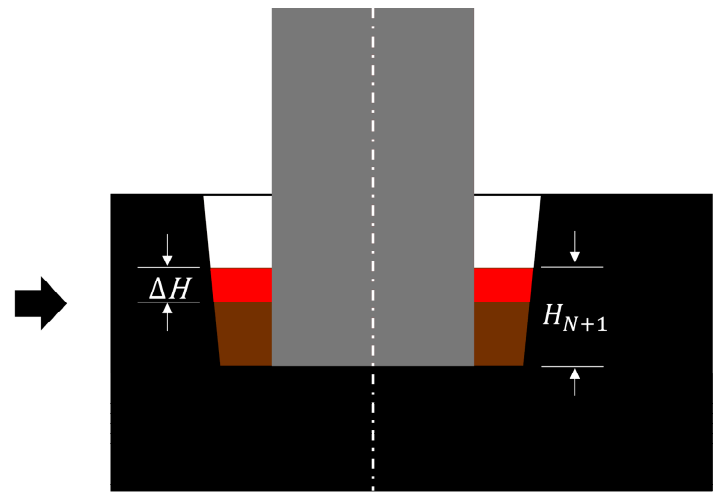

$t=N+d t$ second

Figure 8. The schematic picture of the loads.

$$
\begin{aligned}
& H_{N}=\frac{N}{10} \cdot H_{\text {stubhole }}, N \in[1,10] \\
& T_{\Delta H}=1350{ }^{\circ} \mathrm{C}, t \in(N-1, N]
\end{aligned}
$$

where, $N$ is the current load step number; $H_{\text {stubhole }}$ is the depth of the stub hole, $120 \mathrm{~mm} ; \Delta H$ is the height increment in each load step, $12 \mathrm{~mm}$; $T_{\Delta H}$ is the pouring temperature, $1350{ }^{\circ} \mathrm{C}$, applied to the part corresponding to $\Delta H$.

\subsection{The Pouring Flow Chart}

The whole process had three stages. The first stage was the stub hole-filling. There were four stub holes, and stage 1 , the stub hole filing process, lasted for $40 \mathrm{~s}$ in total, or $10 \mathrm{~s}$ per stub hole. This process had 40 load steps. The second stage started from $41 \mathrm{~s}$ to $100 \mathrm{~s}$, so that the cast iron in the first stub hole could completely solidify. The time increment remained at $1 \mathrm{~s}$ per load step. In the last stage, each step lasted for $4 \mathrm{~s}$ until $1300 \mathrm{~s}$, and the flow chart is given in Figure 9.
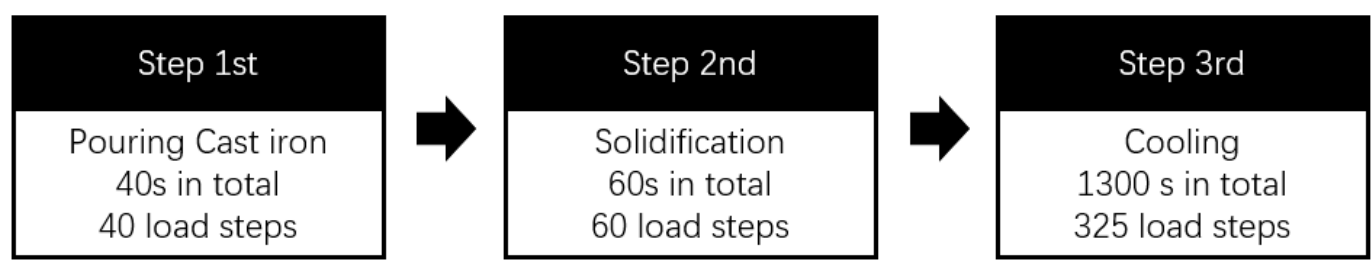

Figure 9. The flow chart of the solution. 


\section{Results and Analysis}

\subsection{Model Validation}

As shown in Figure 10, the temperature contours at $40 \mathrm{~s}, 180 \mathrm{~s}$, and $300 \mathrm{~s}$ after casting are presented. At $40 \mathrm{~s}$, the last stub hole was just filled up (the filling sequence was from left to right in Figure 10), while in the first stub hole, a thin shell of solid phase had already arisen in the inner wall of cast iron. At $180 \mathrm{~s}$, the temperature of cast iron thimbles ranged from $520{ }^{\circ} \mathrm{C}$ to $686{ }^{\circ} \mathrm{C}$, which was much lower than the solidus temperature. At this moment, the cast iron had completely solidified for a period of time. At $300 \mathrm{~s}$, the temperature range of the thimbles was from $397{ }^{\circ} \mathrm{C}$ to $523{ }^{\circ} \mathrm{C}$. Besides, the portion at high temperature was concentrated around the stub holes, while the rest remained at room temperature or slightly exceeded room temperature.

The numerical results were compared with the references for validation. From the numerical investigation results [20], the temperature of the cast iron at $180 \mathrm{~s}$ after pouring ranged from $423{ }^{\circ} \mathrm{C}$ to $635^{\circ} \mathrm{C}$, when the pouring temperature was $1400{ }^{\circ} \mathrm{C}$. According to the measurement [10] with a pouring temperature of $1300^{\circ} \mathrm{C}$, the cooling curve of the cast iron in the first stub hole showed that the temperature ranged approximately from $520{ }^{\circ} \mathrm{C}$ to $760{ }^{\circ} \mathrm{C}$ at $180 \mathrm{~s}$, and from $450{ }^{\circ} \mathrm{C}$ to $500{ }^{\circ} \mathrm{C}$ at $300 \mathrm{~s}$. Thus, the results are in a reasonable range, considering the differences of the dimensions and the compositions of the cast iron between the present model and references.

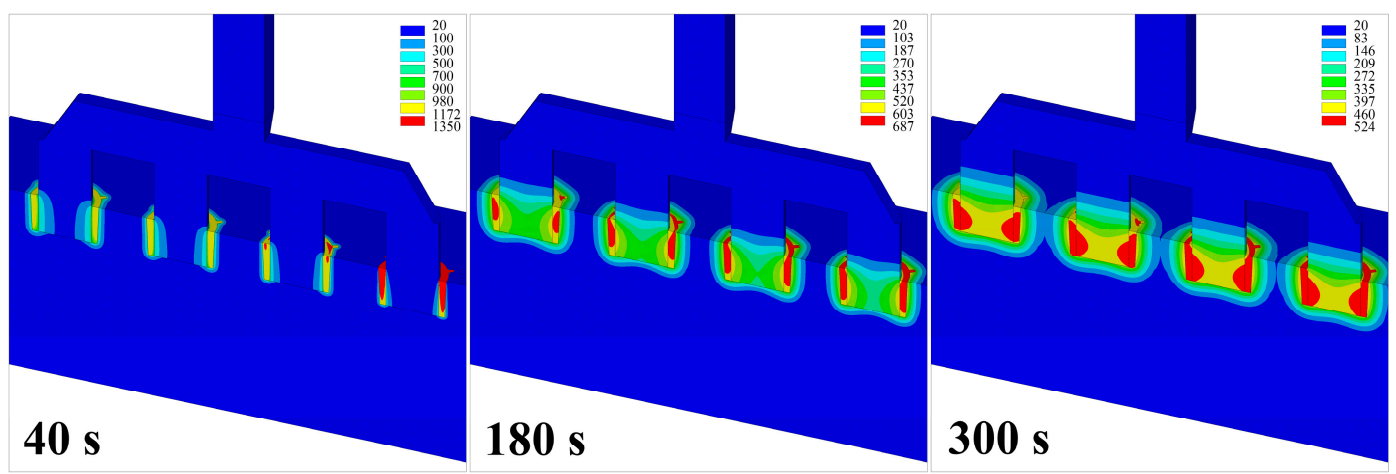

Figure 10. The temperature $\left({ }^{\circ} \mathrm{C}\right)$ contour at $40 \mathrm{~s}, 180 \mathrm{~s}$, and $300 \mathrm{~s}$.

\subsection{Solidification Process Analysis}

Figure 11 shows us the heat transfer rate between the adjacent stub holes over time. The maximum value is only $13 \mathrm{~W}$, due to the restriction of bad thermal conductance of carbon. As a result, the heat from the melt inside one stub hole is hardly dispersed away to affect the stub hole (s) next to it. Also, given that the pouring temperature and the feeding rate stay constant, the changes of temperature over time inside each stub hole are the same, except for a time delay-derived from the non-simultaneous pouring. From a thermal standpoint, it could be implied that the casting sequence could be random under the same pouring conditions. Furthermore, the analysis of anode rodding could be done by taking one stub hole as an example. 

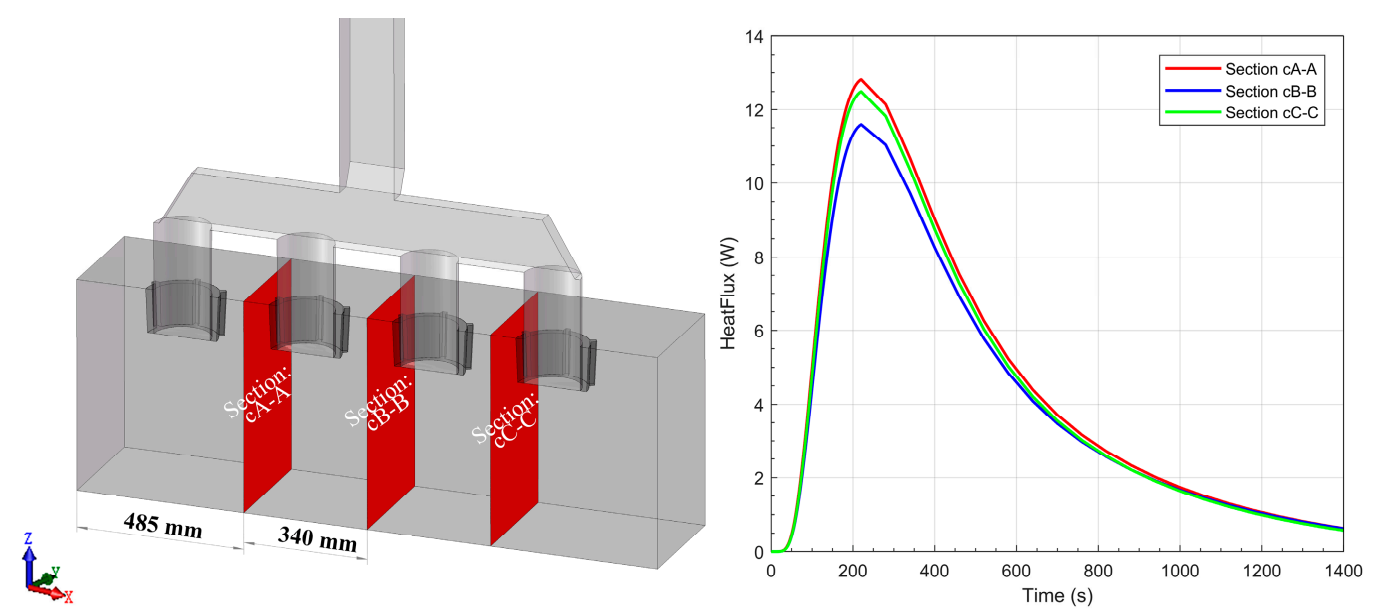

Figure 11. The heat transfer rate between the adjacent stub holes.

Figure 12 shows the temperature contours in the left stub hole at different times. Typically, there are three zones for the eutectic alloy with a freezing range. The part above the liquidus temperature $\left(1172{ }^{\circ} \mathrm{C}\right)$ is the liquid zone, and the part below the solidus temperature $\left(980^{\circ} \mathrm{C}\right)$ is considered to be completely solid, called the solid zone. When the temperature of a part of cast iron is between the liquidus and solidus temperature, it means that this part is a mixture of the liquid and solid phases under solidification, with the primary austenite or graphite precipitating or eutectic transforming. This part could be considered as an entire part, called the mushy zone. At $10 \mathrm{~s}$, the stub hole was filled up, while at about $1 / 3$ height in the bottom, it had already entered mushy zone. During the period from $10 \mathrm{~s}$ to $20 \mathrm{~s}$, the rest of the cast iron entered the mushy zone rapidly. At $20 \mathrm{~s}$, almost all of the cast iron was occupied by the mushy zone. Then, the inner wall and the flute edges started to generate a solid shell, and the shell generally became thicker and thicker. At $65 \mathrm{~s}$, all of the cast iron had solidified, except the junction between the flutes and the thimble. 


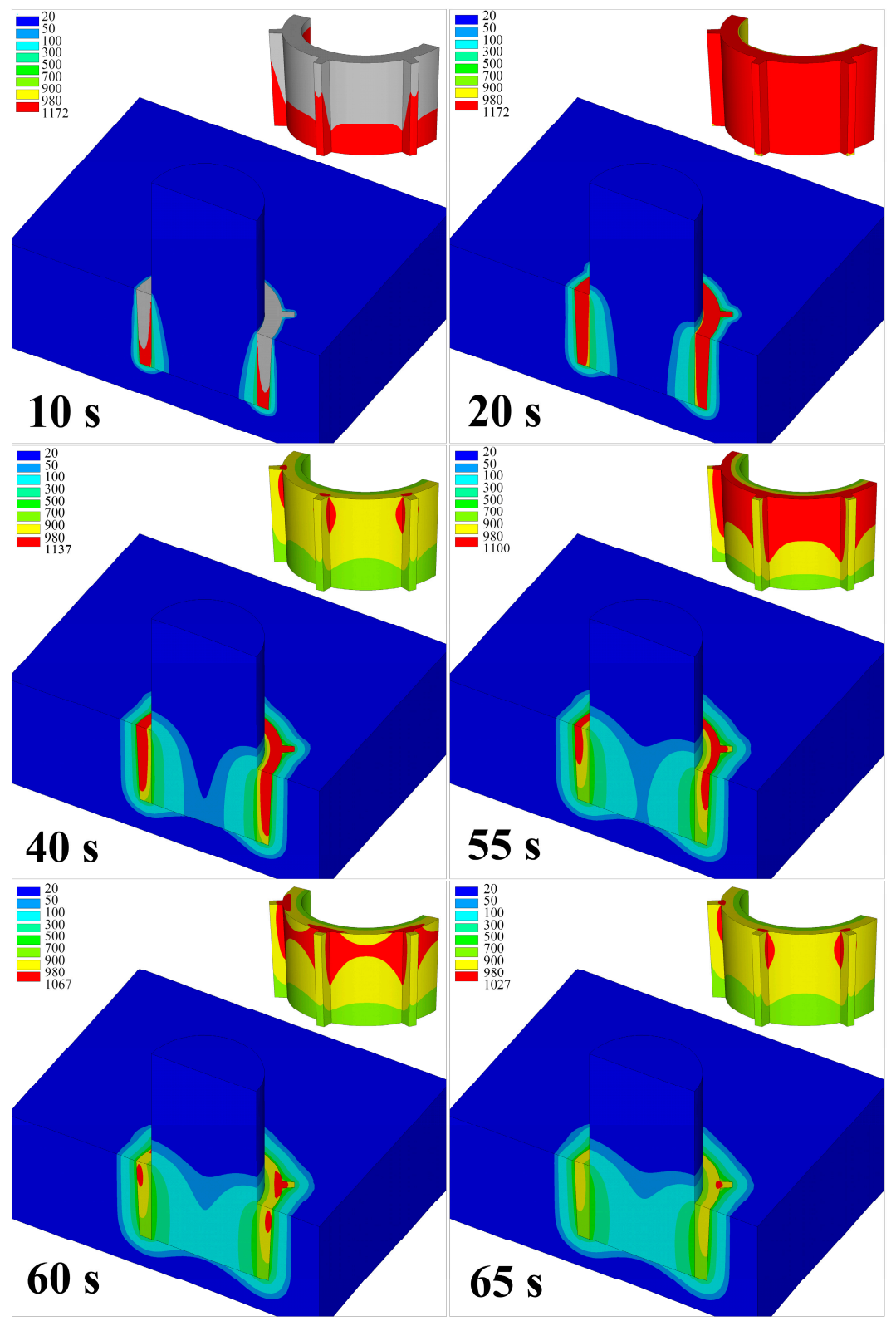

Figure 12. The temperature contours $\left({ }^{\circ} \mathrm{C}\right)$ during solidification of the cast iron in the first stub hole.

As shown in Figure 13, the percentage by volume of the solid zone, mushy zone, and liquid zone over time during solidification of the cast iron in the first stub hole were compared. 


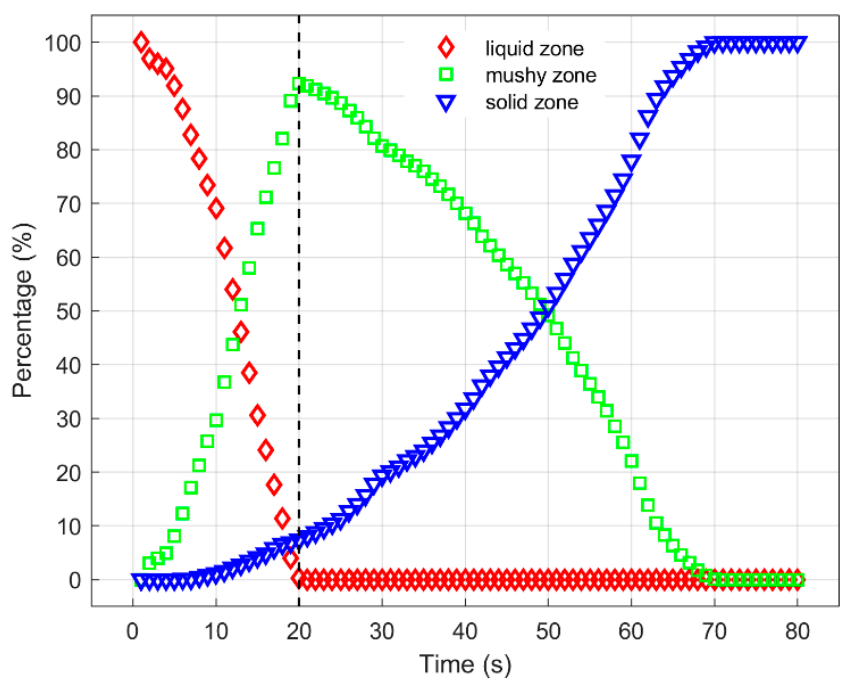

Figure 13. The curve of percentage by volume of three zones over time during solidification.

The three curves were divided into two halves, with the $20 \mathrm{~s}$ time point as the dividing line. In the first half, from $0 \mathrm{~s}$ to $20 \mathrm{~s}$, the percentage by volume of the liquid zone was dropping down, and the percentage by volume of the mushy zone increased quickly. However, the solid volume increased slowly. The liquid zone disappeared at $20 \mathrm{~s}$. Simultaneously, the mushy zone peaked at $92 \%$, indicating that $92 \%$ of the cast iron was undergoing solidification at the same time. In the second half, the fraction of the mushy zone started to decrease, transforming into the solid phase. At about $70 \mathrm{~s}$, the solid phase reached $100 \%$, marking the end of solidification. In addition, it is noted that when the stub hole was filled up at $10 \mathrm{~s}$, even though the solid phase fraction only accounted for less than $1 \%$, the mushy zone fraction was as high as $30 \%$. As a result, it is indispensable to take the stub hole-filling process into account.

Based on the scope of the mushy zone, the solidification mode of the section is categorized into 3 modes [21]. The first is skin-freezing, characterized by gradual freezing, layer by layer. In this circumstance, the mushy zone usually remains narrow compared to the width of the section, and it proceeds gradually from solid to liquid. In comparison, the second is mushy-freezing, characterized by almost simultaneous solidification. The mushy zone is usually very wide during the solidification process and it even runs through the whole section in certain times. As a result, a majority of the section is undergoing simultaneous solidification. The last one is an intermediate mode between the two mentioned. The variation of the mushy zone volume over time, which first increases rapidly and then decreases, is consistent with the characteristics of either mushy-freezing or intermediate-freezing.

The state of the cast iron at a certain position can be reflected on the solidification dynamic curve, which can help to justify the solidification mode. The distance between the solidus and liquidus isotherm on the curve at a specified time point equals the width of the mushy zone. Solidification dynamic curves were drawn by taking several points on L1 and L2 from the bottom height of $60 \mathrm{~mm}$. As shown in Figure 14, $X$ axis represents time, while the $Y$ tick values equal the distance between the selected points and the inner wall divided by the thimble thickness. Curve $I\left(t_{1}\right.$ is the time corresponding to the liquidus temperature) and curve II ( $t_{s}$ is the time corresponding to the solidus temperature) represent the liquidus boundary and the solidus boundary, respectively. 


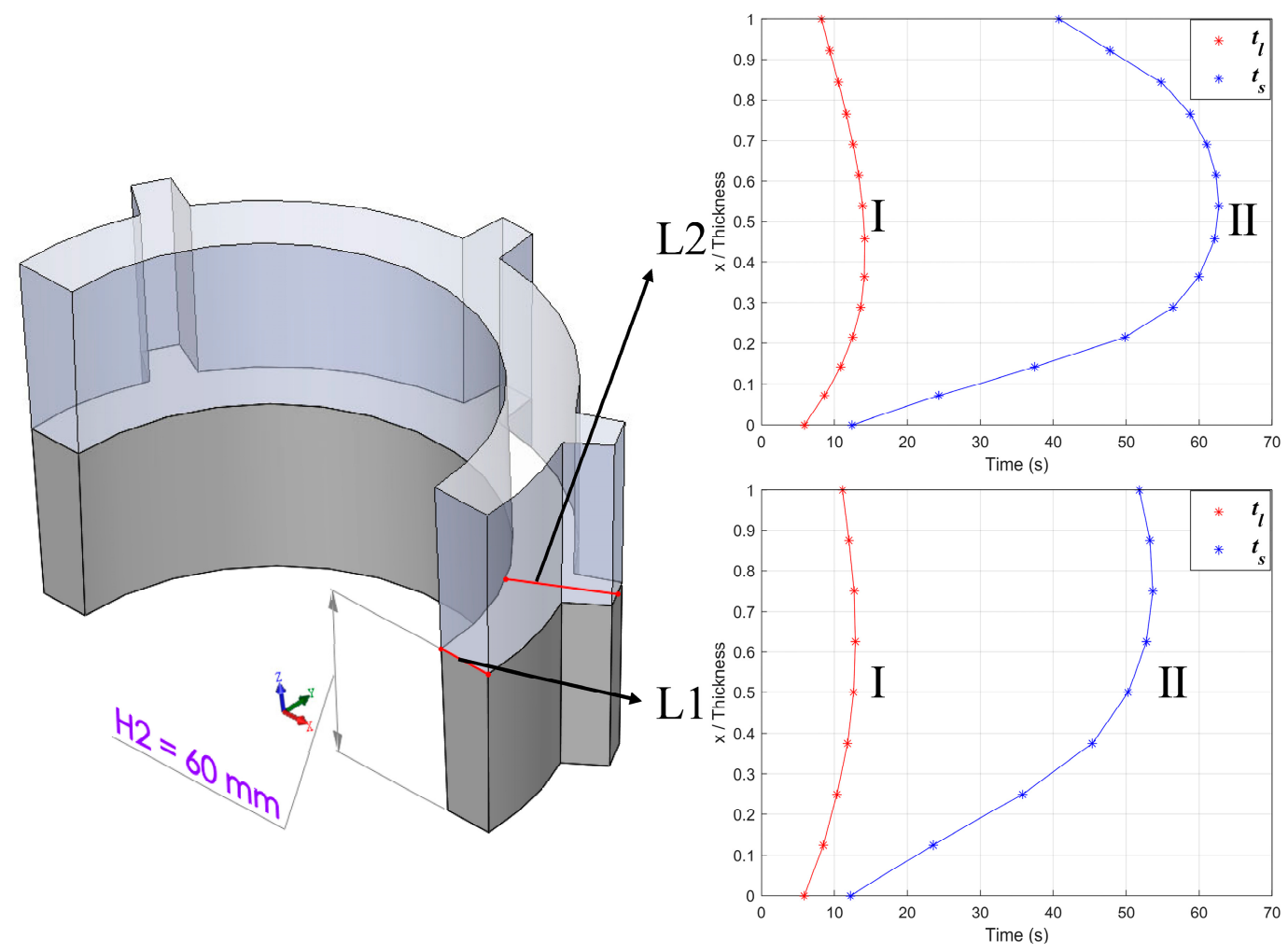

Figure 14. Dynamic solidification curves.

The points on L1 entered the mushy zone rapidly in $5 \mathrm{~s}$, according to the liquid boundary. At about $12 \mathrm{~s}$, all the points were in the mushy zone, which ran throughout the width at this moment. Then, the width of the mushy zone linearly decreased away from the inner wall. When the solidification reached the middle on L1 at $50 \mathrm{~s}$, it accelerated, and the mushy zone disappeared in almost a fairly short time, and nearly simultaneously. The variation of the mushy zone on L2 was similar, except that on L2, the solidification of cast iron proceeded from the two ends to the inside, and it was slower.

From the two curves, the cast iron entered the mushy zone quite quickly. Thus, the scope of mushy zone mainly depends on the time at which freezing ends. The horizontal section where L1 and L2 located is denoted as iA-A, of which the end-of-freeze plot is shown in Figure 15.

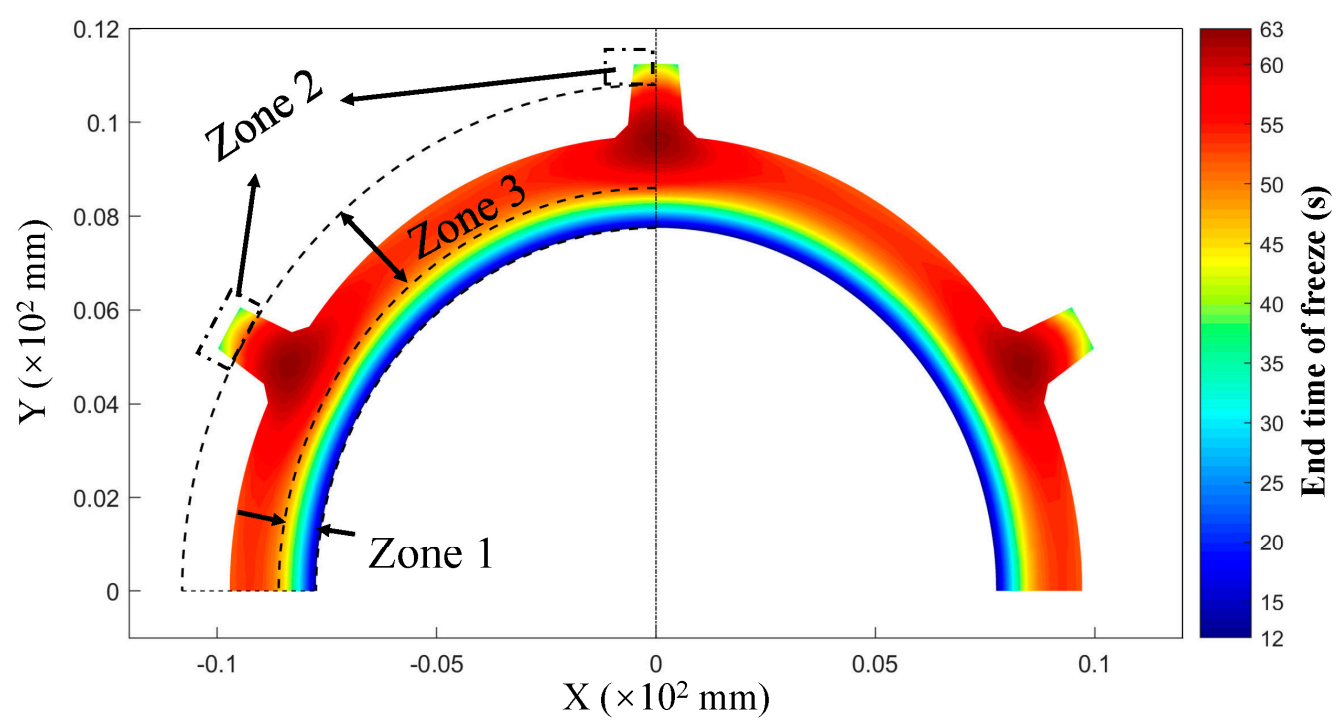

Figure 15. The end-of-freeze contour on the horizontal section. 
In Figure 15, different colors referring to the colorbar represent the time at which each position in the section reaches the solidus temperature, while a boundary of different color could be regarded as a solidus isotherm. According to the sequence of solidification time, the section is divided into three zones, denoted as Zones 1-3. Because of the good thermal conductivity of steel, the inner ring part, denoted as Zone 1, completed solidification first. The solidus isotherm was parallel to the inner wall of the cast iron, and it moved from the inner wall towards the inside. The solidification process proceeded layer-by-layer in Zone 1. Although the thermal conductivity of carbon is not as good as steel, the flutes were relatively small in size and extended into the carbon. As a result, at the end of solidification of Zone 1, solidification gradually completed layer-by-layer from the outside to the inside, in the part denoted as Zone 2. The remaining part, denoted as Zone 3, solidified later than both Zones 1 and 2. Zone 3 was quite different from Zones 1 and 2. It was very hard to find the solidus isotherm. Even though the isotherms did exist in the junction between the thimble part and the flutes, the time gradient was only about $3 \mathrm{~s}$. So, in Zone 3, except the cast iron in the junction part, which solidified in the final, the remaining parts solidified at around $55 \mathrm{~s}$.

Combined with the end-of-freeze and solidification dynamic curves, the solidification mode of the section is clear. It tends to be intermediate-freezing, transiting from skin-freezing towards mushy-freezing, in which Zones 1 and 2 are skin-freezing and Zone 3 is mushy-freezing.

The vertical sections in the L1 and L2 directions are denoted as sections iB-B and iC-C respectively, and the end-of-freeze contour is also presented, as in Figure 16.

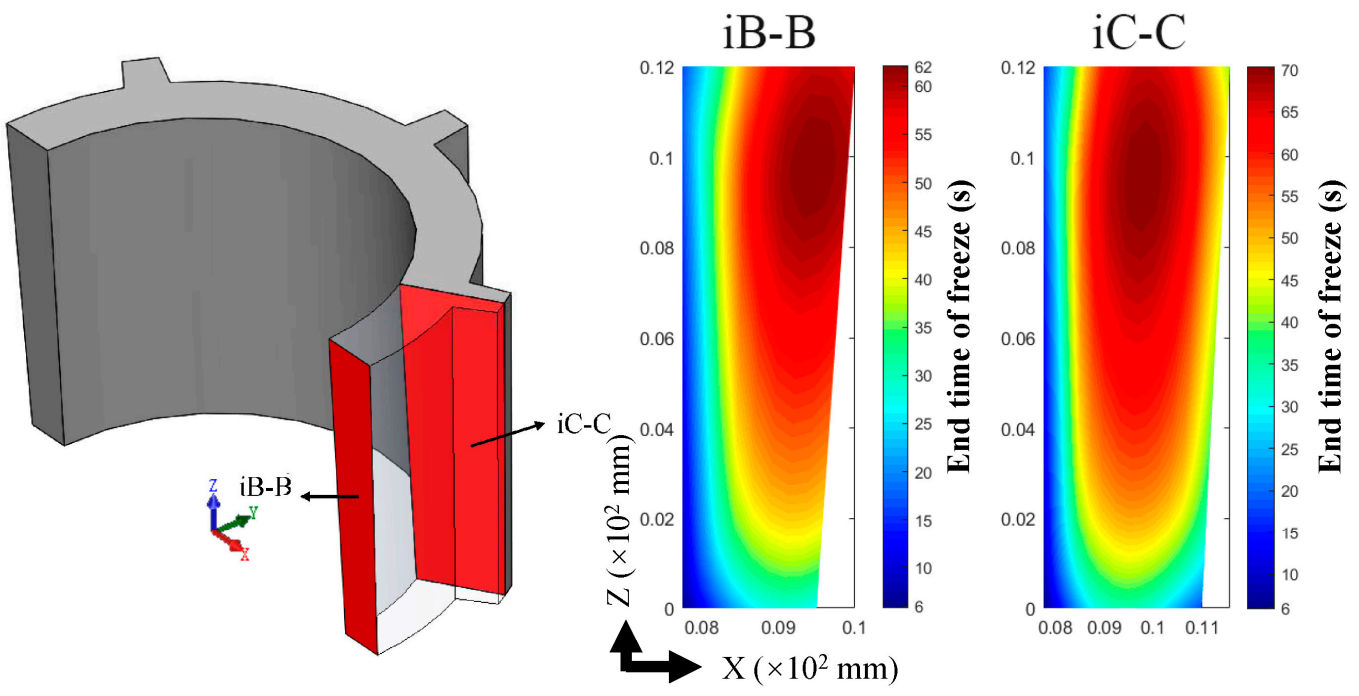

Figure 16. The end-of-freeze contours on vertical sections.

Due to the chilling effect, solid shell formed rapidly on the inner side of the cast iron, on both the two vertical sections. Subsequently, the difference between the shapes of the solidus isotherm on the two sections rose. On iB-B, the solidus isotherm was "L" shaped, moving from the inner wall to the outer, and from the bottom towards the top, while that on $\mathrm{iC}-\mathrm{C}$ showed a shrinking " $\mathrm{U}$ ", because it was thicker and affected by the flute. It could be implied that the end-of-freeze plot on the horizontal section was quite similar according to that on the vertical plot. The characters in Figure 15 could be extended to all the horizontal sections.

The vertical sequence of solidifying determines whether the feeding channel is unobstructed or not. There was no cross or narrowed bridge in the "end-of-freeze" isotherm, and the overall solidification process was from the bottom up to the top. From the perspective of thermal analysis, the feeding channel was unobstructed, and there is little chance of shrinkage porosity [9]. Note that the fluidity of the melt, as well as the critical solid phase fraction, was neglected here. Hence, further research is needed. 


\subsection{Cooling Curves}

During solidification, the cooling curve is of great importance, and the shape of the curve has great effects on the final microstructure. At first, three points at mid-height of the stub hole were taken, denoted as i1, i2, and i3 respectively. i1 is $2.5 \mathrm{~mm}$ away from the stub surface horizontally and i3 is $2.5 \mathrm{~mm}$ from the carbon block surface, while i2 is at the mid-point. The cooling curves of the three points before $200 \mathrm{~s}$ are presented in Figure 17. All of the curves peaked at $1350{ }^{\circ} \mathrm{C}$ at the same time, due to the cast iron injecting at $5 \mathrm{~s}$, and dropping down afterwards. The temperature of i1 dropped the most quickly, and the curve corresponding to i1 first experienced fast cooling, and then the change became slower. The maximum difference between i1 and the other two could be $180{ }^{\circ} \mathrm{C}$ or so. In contrast, i2 and i3 had relatively slower dropping curves. There were obvious platforms near the liquidus and solidus temperature on the cooling curves of i2 and i3, which were attributed to the release of latent heat compensating the heat loss and slowing down the cooling. However, the curve of i1 was smooth, due to its fast cooling rate.

Then, at $30 \mathrm{~mm}$ below and above i2, two points were taken, denoted as i4 and i5. The curves of the two points is as in Figure 18. The difference between the three curves was not as obvious as that in Figure 17. i4 was dropping a little faster than i2 and i5. There were also platforms derived from the phase change.

It is worth noting that during the stub hole-filling process, i.e., the first $10 \mathrm{~s}$, the temperature drops of the five points selected exceeded $100{ }^{\circ} \mathrm{C}$. Especially, from the beginning to the end of the stub hole-filling process, the temperature drop of $\mathrm{i} 1$, the point close to the stub, could be as high as $200^{\circ} \mathrm{C}$. It could also be concluded that the temperature drop of cast iron during the stub hole filling process was not negligible.

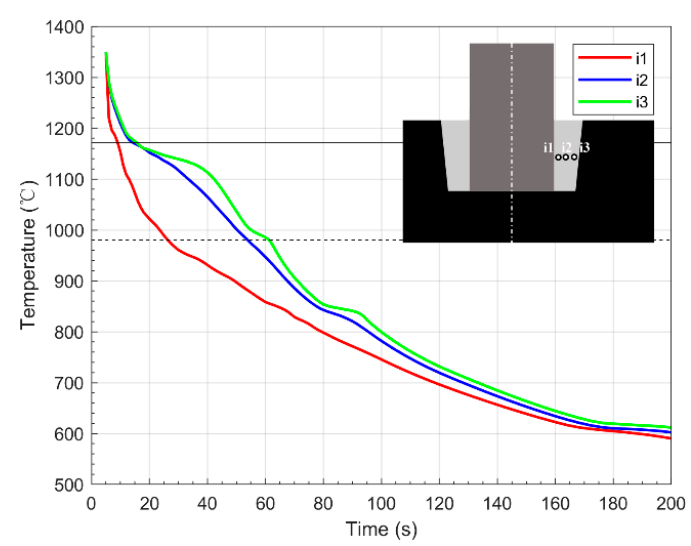

Figure 17. The cooling cures of i1, i2, and i3 in cast iron.

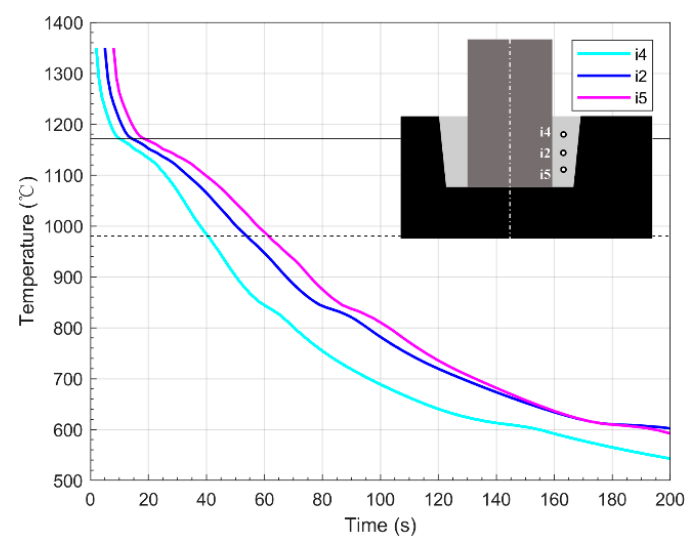

Figure 18. The cooling cures of $\mathrm{i} 4, \mathrm{i} 2$, and i5 in cast iron. 
During the casting cooling process, the stub acts as a chill and it is the main medium for cast cooling, through which the cooling process could be controlled. Also, according to [22], the air gap is a function of both of the solidus temperature of cast iron and the temperature of the stub at the instant when the cast iron reaches the solidus temperature. Even if the air gap varies by $1 \times 10^{-6} \mathrm{~m}$, it would lead to a change of $\pm 5 \%$ in the anode voltage drop. Thus, the temperature history of the stub is important for the cast iron cooling and the estimation of the air gap size.

Seven points in different positions, denoted as st1-st7, were taken in the stub. Points st1-st3 are $10 \mathrm{~mm}$ to the interface between the stub and cast iron, and their heights are $30 \mathrm{~mm}, 60 \mathrm{~mm}$, and $90 \mathrm{~mm}$ to the stub bottom. Points st4-st6 lie on the symmetry axis of the stub, and their heights corresponds to points st1-st3. Point st7 is located at the symmetry axis, $50 \mathrm{~mm}$ from the top of the cast iron. The cooling curves are shown in Figure 19. It is obvious that all the points experienced a process in which the temperature rose rapidly, and then reduced. Initially, the stub was under room temperature, and with the molten iron injected, the stub was heated up by the cast iron. As the cast iron cooled down, once the heat from the cast iron was not sufficient to compensate the heat dissipation of the stub, the temperature of the stub would start to reduce.

The temperature of three points under the stub surface, st1-st3, peaked at around $115 \mathrm{~s}$ at $500-550{ }^{\circ} \mathrm{C}$, while after $450 \mathrm{~s}$, the temperatures of the points on the symmetry axis, st4-st6, reached the maximum values, which were between $390-440{ }^{\circ} \mathrm{C}$. The temperature of point st 7 rose very slowly, and it could be implied that the part above st7 would never exceed $210^{\circ} \mathrm{C}$. In addition, when the cast iron in the selected stub hole would solidify completely at $70 \mathrm{~s}$, the temperature of the stub was still rising.
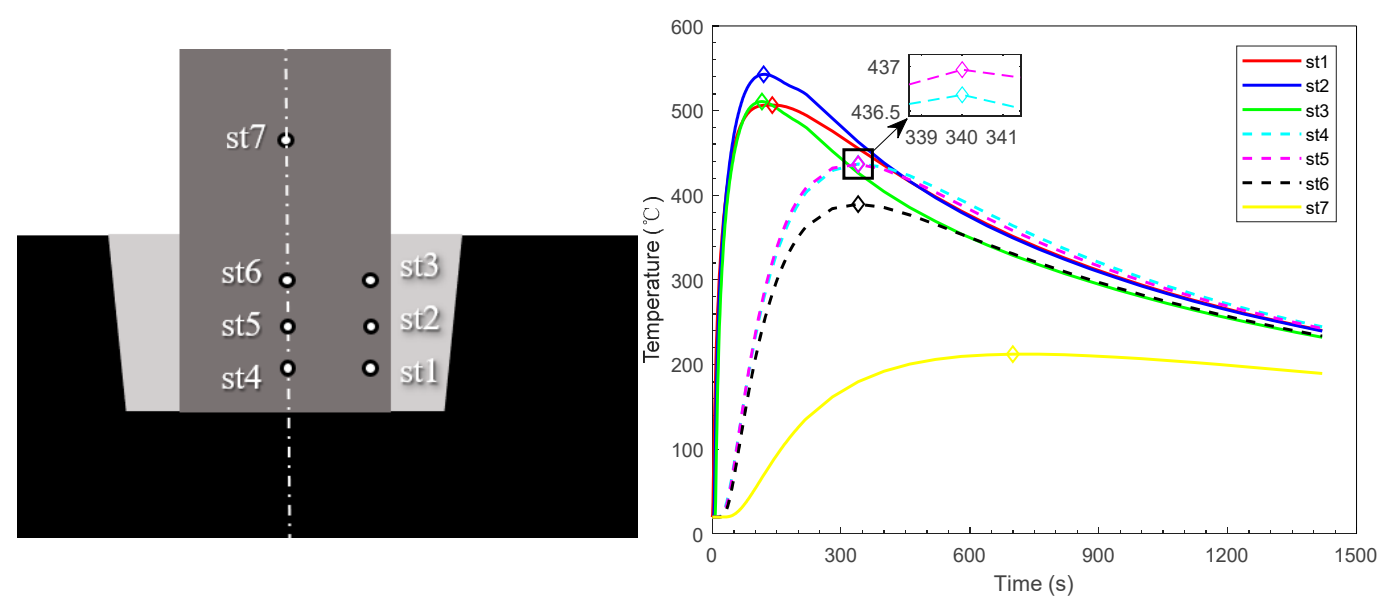

Figure 19. Schematic picture of the points selected in the stub and the cooling curves.

Figure 20 shows the cooling curves of several points in the carbon block. Points cb1-cb3 are $10 \mathrm{~mm}$ to the cast iron-to-carbon interface, points $\mathrm{cb} 4-\mathrm{cb} 6$ are located at the middle of two adjacent stub holes and about $70 \mathrm{~mm}$ to the cast iron-to-carbon interface, and point 7 is situated at the symmetry axis of the stub hole, and $10 \mathrm{~mm}$ to the bottom of the stub hole. The heights of cb1-cb6 are the same with those of st1-st6, respectively. The points close to the cast iron-to-carbon interface could be heated up to about $400{ }^{\circ} \mathrm{C}$. The temperatures of the points in the middle of the two adjacent stub holes, and the point under the stub hole bottom rose up slowly and could only be up to about $210^{\circ} \mathrm{C}$. Overall, the temperature of the carbon block was much lower than that of the stub. 

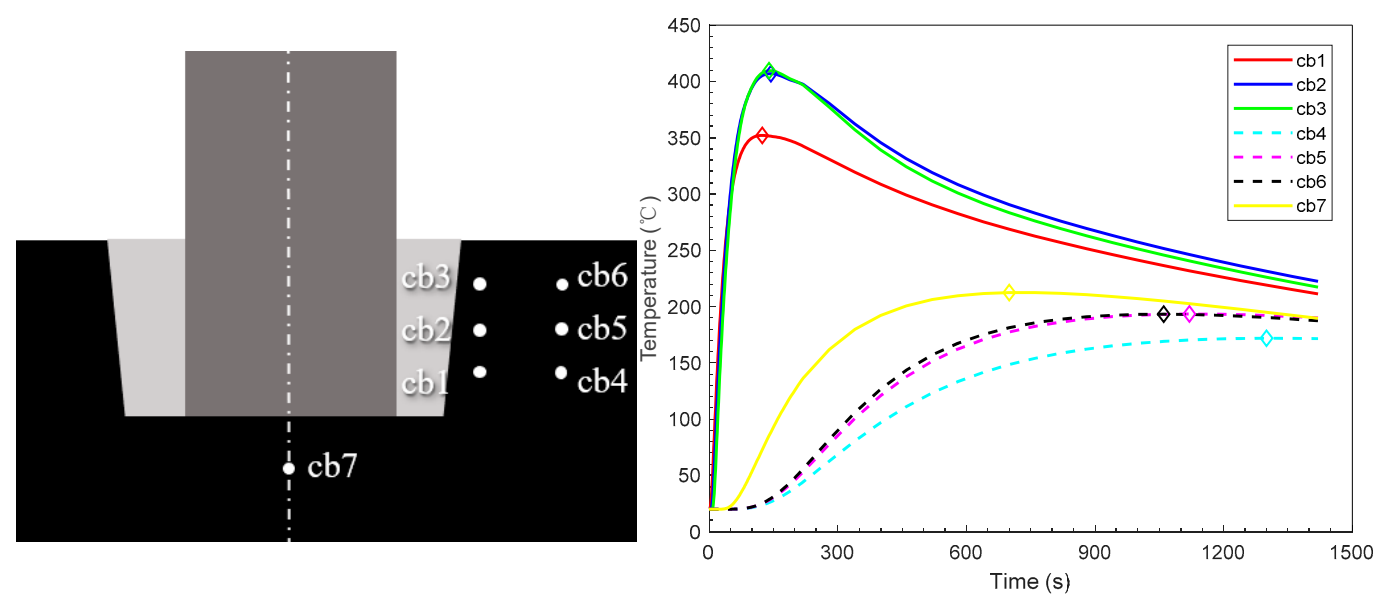

Figure 20. Schematic picture of the points selected in the carbon and the cooling curves.

Besides, as the distance to the cast iron getting farther, the temperature become lower and lower, and the cooling rate become increasingly slow. It could be implied that the portion of the assembly over $200{ }^{\circ} \mathrm{C}$ only concentrated around the stub hole.

\subsection{Cooling Rate and Its Distribution}

The cooling curve of point i2 in Figure 17 was derived, thus obtaining its first-order differential curve, which could represent the curve of cooling rate over time as shown in Figure 21. The points, denoted as $\mathrm{A}$ and $\mathrm{B}$, represent the time at which the curve passes through the liquidus and solidus temperature.

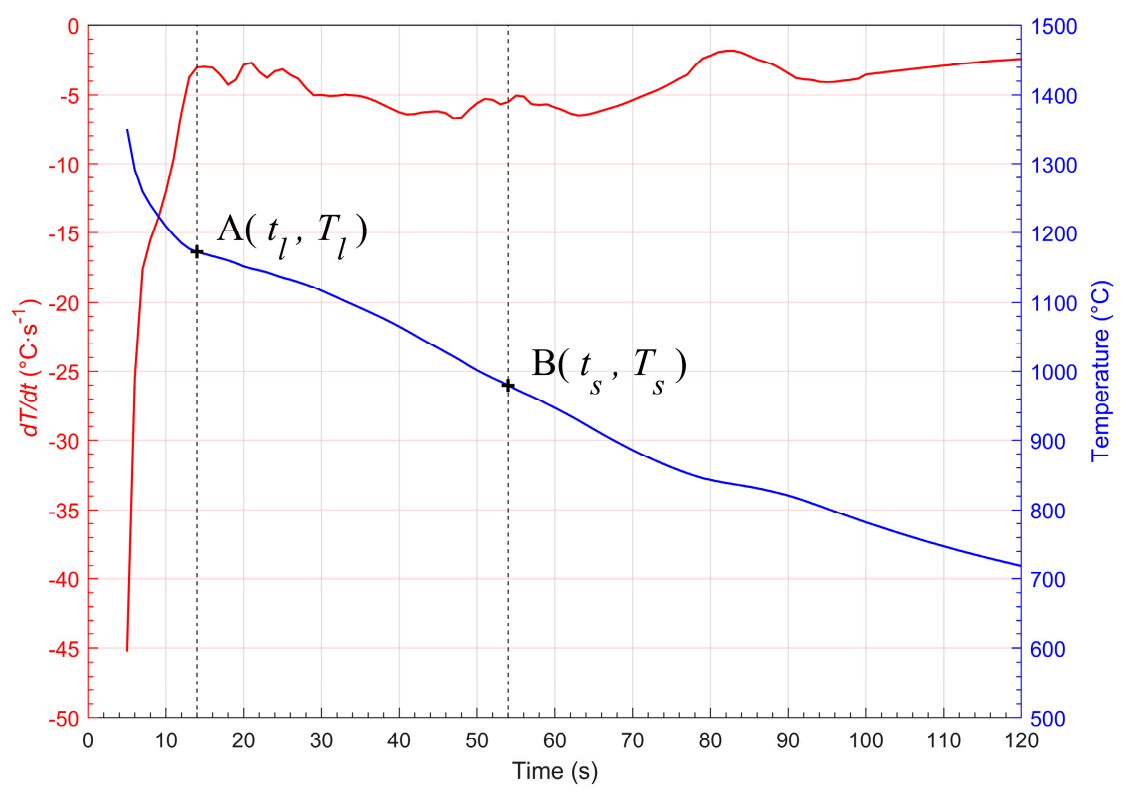

Figure 21. The cooling curve and the first-order differential curve of point i2.

The heat dissipation of the cast iron could be regarded as a process in which heat flow passes through different thermal resistances (reverse of the thermal conductance) under the temperature difference between the cast iron, the stub, and the carbon. When the cast iron was injected, the temperature difference, which acted as the driving force, was the maximum, so the cooling rate (the absolute value of the value corresponding to the curve) was also the maximum, which was the so-called chilling effect. Then, with the cast iron cooling down rapidly and the stub heated up, the temperature difference dropped rapidly. So, the cooling rate kept plunging until the cooling 
curve reached the time corresponding to point A. At this moment, the cooling rate curve reached the first local minimum value, because the generation of the latent heat of phase change increased the thermal resistance of the cast iron. After point A, the curve became slower. The cooling rate fluctuated at first. Even so, it could be regarded as being constant during this period, considering the magnitude of fluctuation. However, with the gradual precipitation of the solid phase, the latent heat became less and less, and the cooling rate gradually rose. At point $B$, the temperature reached $979{ }^{\circ} \mathrm{C}$, and solidification finished. A local minimum value of the cooling rate occurred at the point $\mathrm{B}$, which was the case because there was no more enhancement of convection to the thermal conductivity, and the cast iron-to-carbon air gap opened up, leading to an increase of the cast iron-to-carbon thermal contact resistance. After point $B$, the temperature difference and the conductivity of stub under high temperature become smaller, and the cooling rate kept at a low level. In the period between $75 \mathrm{~s}$ and $85 \mathrm{~s}$, the cooling rate curve fluctuated due to a solid-solid phase change.

Referring to the method in reference, the cooling rate, denoted as $R_{c}$, between the solidus temperature and liquidus temperature was defined as Equation (8):

$$
R_{\mathrm{c}}=\frac{T_{l}-T_{s}}{t_{l}-t_{s}}
$$

where, $T_{l}$ and $T_{s}$ is the liquidus temperature and solidus temperature, ${ }^{\circ} \mathrm{C} ; t_{l}$ and $t_{s}$ are the times when the cast iron reaches $T_{l}$ and $T_{s}, \mathrm{~s}$, respectively.

To some extent, the cooling rate distribution could reflect the phase distribution in the same casting. The distributions of cooling rate on the three sections mentioned previously, iA-A, iB-B, and iC-C are given in Figure 22.
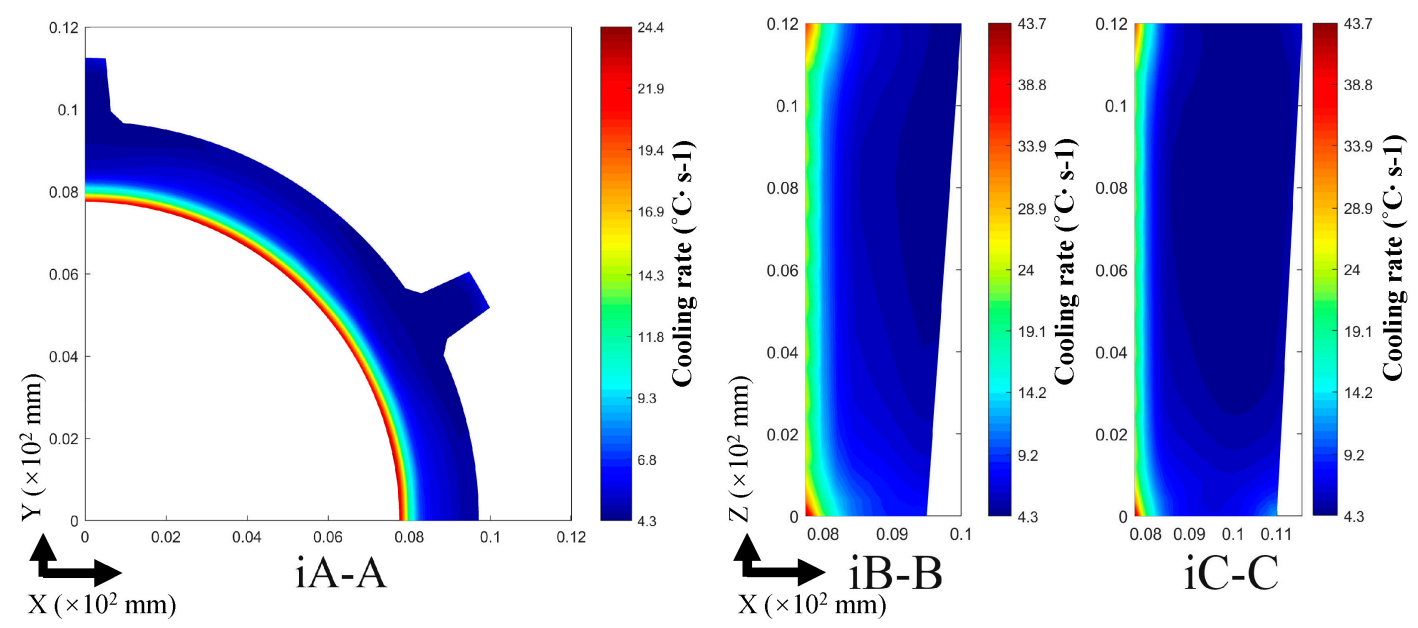

Figure 22. The cooling rate distribution on different sections.

The cooling rate was between $4.3^{\circ} \mathrm{C} \cdot \mathrm{s}^{-1}$ and $47.3^{\circ} \mathrm{C} \cdot \mathrm{s}^{-1}$. Comparing with the results in the reference [13], in which the cooling rate was between $5.3^{\circ} \mathrm{C} \cdot \mathrm{s}^{-1}$ and $153^{\circ} \mathrm{C} \cdot \mathrm{s}^{-1}$, the results are in a reasonable range, given that the cooling rate is affected by the geometry, casting size, and thermal conductance of the materials. In section iA-A, the cooling rate is clearly layered, decreasing from the inner wall to the outer surface of the cast iron. Similarly, the cooling rate distribution in iB-B is also layered, but that in section $\mathrm{iC}-\mathrm{C}$ is an inverted J-shape with a big "cold core" that is close to the carbon, because section $\mathrm{iC}-\mathrm{C}$ is much thicker in the radial direction. The horizontal gradient of the cooling rate is denser than the vertical gradient. As a result, it could be implied that the phase composition gradient is also mainly along the horizontal direction. 


\section{Conclusions}

A transient thermal finite element model was developed to simulate the anode rodding process using APDL language based on the ANSYS software. In the model, the birth-death element function was first applied to the numerical simulation of the anode rodding process, in which the heat transfer during the stub hole-filling process was taken into account, which could make the model closer to the reality.

The conclusions are as follows:

1. During the filling process, the cooling rate was the fastest, and the temperature drop could reach $200{ }^{\circ} \mathrm{C}$ in certain places. At $10 \mathrm{~s}$ after pouring started, when the stub hole was filled up, up to $30 \%$ of cast iron by volume was solidifying. As a result, the heat transfer during stub hole-filling was non-negligible. At about $70 \mathrm{~s}$, the cast iron could solidify completely.

2. The cast iron close to the stub solidified prior to that which was close to carbon. The solidification mode was intermediate-freezing, transiting from skin-freezing, towards mushy-freezing. From the thermal point of view, the end-of-freeze isotherm was vertical without any cross or bridge, indicating little change of shrinkage porosity.

3. The temperatures of the stub and carbon rose at first, and then reduced. The temperature of the stub was much higher, and rose up more quickly than that of the carbon. In addition, a portion of the anode assembly over $200^{\circ} \mathrm{C}$ concentrated around the stub hole.

4. The cooling rate of the cast iron during solidification dropped rapidly before it arrived at the liquidus temperature, and then it fluctuated. The extreme point showed up at the liquidus temperature and solidus temperature, respectively. The average cooling rate during solidification ranged from $4.3^{\circ} \mathrm{C} \cdot \mathrm{s}^{-1}$ to $43.7^{\circ} \mathrm{C} \cdot \mathrm{s}^{-1}$. The cooling rate gradient in the radial direction was greater than the vertical direction, and the cooling rate in the radial direction was gradually reduced from the inner wall of the cast iron to the outer surface.

Author Contributions: T.L. developed the model and wrote the manuscript. W.T. contributed to software guidance, results and discussion, and revision of the manuscript. Z.W. provided a high-performance computer, and contributed to the design of the anode, the discussion, and the information on smelters. X.L. and J.H. provided useful suggestions and information.

Funding: This research was funded by [National Natural Science Foundation of China] grant number [51804071, $51434005,51874086,51804069,51804070$ ] and [Ministry of Education of the People's Republic of China] grant number [N162503004, N162502002]. The APC was funded by [National Natural Science Foundation of China] grant number [51804071] and [Ministry of Education of the People's Republic of China] grant number [No. N162503004].

Conflicts of Interest: The authors declare no conflict of interest.

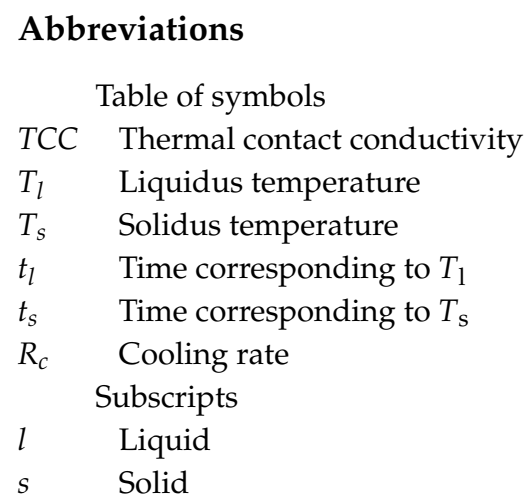




\section{References}

1. Molenaar, D.; Kilpatrick, T.; Montalto, A. Experimental investigation of factors affecting the electrical performance of the stub to carbon connection. In Proceedings of the TMS Light Metals, San Antonio, TX, USA, 3-7 March 2013; pp. 1359-1364.

2. Gunasegaram, D.R.; Molenaar, D. Towards improved energy efficiency in the electrical connections of Hall-Heroult cells through Finite Element Analysis (FEA) modeling. J. Clean. Prod. 2015, 93, $174-192$. [CrossRef]

3. Urrutia, A.; Celentano, J.D.; Gunasegaram, R.D. Modeling and Simulation of the Gray-to-White Transition during Solidification of a Hypereutectic Gray Cast Iron: Application to a Stub-to-Carbon Connection Used in Smelting Processes. Metals 2017, 7, 549. [CrossRef]

4. Li, X. Casting Handbook: Vol. 5 Casting Process, 3rd ed.; China Machine Press: Beijing, China, 2011; pp. $20-40$. ISBN 978-7-111-34171-0. (In Chinese)

5. Zhang, B. Casting Handbook: Vol. 1 Cast iron, 3rd ed.; China Machine Press: Beijing, China, 2013; pp. $15-60$. ISBN 978-7-111-32234-4. (In Chinese)

6. Jabbari Behnam, M.M.; Davami, P.; Varahram, N. Effect of cooling rate on microstructure and mechanical properties of gray cast iron. Mater. Sci. Eng. A 2010, 528, 583-588. [CrossRef]

7. Choudhary, S.K.; Ghosh, A. Mathematical model for prediction of composition of inclusions formed during solidification of liquid steel. ISIJ Int. 2009, 49, 1819-1827. [CrossRef]

8. Molenaar, D.; Sadler, B.A. Anode rodding basics. In Proceedings of the TMS Light Metals, San Diego, CA, USA, 16-20 February 2014; pp. 1263-1268.

9. Viswanathan, S.; Sikka, V.K.; Brody, H.D. Using solidification parameters to predict porosity distributions in alloy castings. JOM 1992, 44, 37-40. [CrossRef]

10. Trempe, O.; Larouche, D.; Ziegler, D.; Guillot, M.; Fafard, M. Real Time Temperature Distribution during Sealing Process and Room Temperature Air Gap Measurements of a Hall-Héroult Cell Anode. In Proceedings of the TMS Light Metals, San Diego, CA, USA, 27 February-3 March 2011; pp. 991-996. [CrossRef]

11. Pedersen, K.M.; Tiedje, N. Temperature measurement during solidification of thin wall ductile cast iron. Part 1. Measurement 2008, 41, 551-560. [CrossRef]

12. Zhang, H.; Zhao, W. Thermal Measurement and Instrument (in Chinese), 2nd ed.; Metallurgical Industry Press: Beijing, China, 2006; p. 384. ISBN 978-7-5024-6435-6.

13. Gunasegaram, D.R.; Molenaar, D. Rodding in Hall-Héroult Cells: An Fea Model that Predicts Room Temperature Mechanical Properties and Cracking Tendency of Thimbles. In Light Metals 2014; Grandfield, J., Ed.; Springer International Publishing: Cham, Switzerland, 2016; pp. 1287-1292.

14. Holman, J.P. Heat Transfer, 10th ed.; McGraw-Hill: New York, NY, USA, 2010; pp. 139-192. ISBN 978-0-07-352936-3.

15. Chaouki, H.; Baiteche, M.; Jacques, A.; Gosselin, E.; Alamdari, H.; Fafard, M. Finite Element Analysis of Slot Size Effect on the Thermal-Electrical Behaviour of the Anode. In Proceedings of the TMS Light Metals, San Diego, CA, USA, 26 February-2 March 2017; pp. 1315-1323.

16. Celentano, D.J.; Cruchaga, M.A.; Schulz, B.J. On the effect of natural convection on the thermal-microstructural evolution in gray cast-iron solidification. Metall. Mater. Trans. B 2006, 37, $253-264$. [CrossRef]

17. Trovant, M.; Argyropoulos, S. Finding boundary conditions: A coupling strategy for the modeling of metal casting processes: Part I. Experimental study and correlation development. Metall. Mater. Trans. B 2000, 31, 75-86. [CrossRef]

18. Fortin, H.; Kandev, N.; Fafard, M. FEM analysis of voltage drop in the anode connector induced by steel stub diameter reduction. Finite Elem. Anal. Des. 2012, 52, 71-82. [CrossRef]

19. Allard, B.; Lacroix, S.; Noyel, J.-P.; Rivoaland, L. Modelling of collector bar sealing in cathode blocks with cast-iron. In Proceedings of the TMS Light Metals, San Francisco, CA, USA, 15-19 February 2009; pp. 1097-1102.

20. Gunasegaram, D.R.; Molenaar, D. A fully coupled thermal-electrical-mechanical transient FEA model for a 3D anode assembly. In Proceedings of the TMS Light Metals, San Antonio, TX, USA, 3-7 March 2013; pp. 1341-1346. 
21. Plutshack, L.A.; Suschil, A.L. Riser Design. Metals Handbook-Vol. 15 Casting, 9th ed.; Stefanescu, D.M., Davis, J.R., Eds.; ASM International: Materials Park, OH, USA, 1988; pp. 617-634. ISBN 0-87170-007-7.

22. Richard, D.; Fafard, M.; Lacroix, R.; Clery, P.; Maltais, Y. Aluminum reduction cell anode stub hole design using weakly coupled thermo-electro-mechanical finite element models. Finite Elem. Anal. Des. 2001, 37, 287-304. [CrossRef] 